\title{
Cartografiando saberes, grupos ocupacionales, instituciones, agentes y redes. El caso del Segundo Congreso Panamericano de Educación Física, México, 1946
}

Mapping knowledge, occupational groups, institutions, agents and networks. The case of the Second Pan American Congress of Physical Education, Mexico, 1946

Dr. Pablo Ariel Scharagrodsky ${ }^{1}$

\section{Resumen}

\begin{abstract}
El siguiente trabajo analiza, a partir de una historia social y cultural de la educación, el Segundo Congreso Panamericano de Educación Física realizado en México en 1946. Indaga al congreso -el primero de semejante envergadura en México- como un lugar que permite identificar saberes en común, significados dominantes y puntos de tensión sobre la educación física. Conceptualiza al evento como una caja de resonancia que permite cartografiar instituciones, personas, redes y grupos de especialistas, los cuales pugnaron por imponer ciertos sentidos y significados sanitarios, educativos y recreativos en el campo específico. Nuestra hipótesis sugiere que el evento internacional se convirtió en un terreno no sólo de legitimación de la especialidad en términos transnacionales, sino también de jerarquización y de mayor visibilización de ciertos países, expertos e instituciones por encima de otras..
\end{abstract}

Palabras clave: congreso, educación física, panamericanismo, cuerpo, pedagogía

Abstract

Based on a social and cultural history of education, the following article analyzes, the Second Pan American Congress of Physical Education held in Mexico in 1946. It investigates the congress -the first of such magnitude in Mexico- as a place that allows identifying common knowledge,

${ }^{1}$ Universidad de Quilmes (UNQ) / Universidad Nacional de La Plata (UNLP), Argentina. Correo electrónico: pas@unq.edu.ar 
dominant meanings and points of tension about physical education. It conceptualizes the event as a sounding board that maps institutions, people, networks and groups of specialists, which struggled to impose certain health, educational and recreational senses and meanings in the specific field. Our hypothesis suggests that the international event became a field not only of legitimation of the specialty in trans-national terms, but also of hierarchization and greater visibility of certain countries, experts and institutions over others.

\section{Keywords: congress, physical education, Pan-Americanism, body, pedagogy}

\section{Introducción}

En junio de 1943 se realizó el Primer Congreso Panamericano de Educación Física en la ciudad de Río de Janeiro, Brasil. Con la participación de representantes, delegados e interesados (maestros, profesores de educación física, médicos, entrenadores, etc.) de trece países americanos (Bolivia, Brasil, Chile, Colombia, Costa Rica, Cuba, Guatemala, EEUU, México, Panamá, Paraguay, Perú y Uruguay) y a partir de un intenso trabajo en diversas secciones temáticas (pedagogía aplicada a la educación física, biología aplicada a educación física, política educacional vinculada con la educación física, organización y administración de la educación física y temas generales relacionados con la disciplina) se discutieron distintas problemáticas vinculadas con la educación física, el mundo deportivo, la salud física y la educación en general.

Por primera vez, delegados y autoridades de varias naciones americanas con un fuerte apoyo estatal, bajo el paraguas del panamericanismo ${ }^{2}$, se reunieron para discutir y acordar políticas corporales consensuadas, tipos de intervenciones ideales, prácticas y saberes científicos e intereses comunes vinculados con dicho campo, tanto para el plano nacional como para el americano. Entre las diversas conclusiones consensuadas durante el congreso se mencionó la necesidad de consolidar e institucionalizar este tipo de eventos:

Os delegados oficiais, das nações aqui representadas decidem considerar o Congresso Panamericano de Educação Física como instituição de caráter permanente, com as finalidades de manter latente o intercâmbio e colaborar com os governos, e instituições

\footnotetext{
2El panamericanismo fue incorporado al ámbito de las relaciones internacionales a fines del siglo XIX y principios del XX. Se asoció con una serie de conferencias que se iniciaron, a instancias del gobierno estadounidense, en Washington en 1889 y continuaron durante la primera mitad del siglo XX. En 1890 se creó la Unión Internacional de Repúblicas Americanas, producto de la Primera Conferencia de Estados Americanos. En 1910 esta misma agrupación se convirtió en Unión Panamericana y en 1948 adoptó el nombre de Organización de los Estados Americanos (O. E. A.). En la primera mitad del siglo XX, frente al creciente poder de los Estados Unidos y a otras tensiones geopolíticas, se organizaron una importante cantidad y variedad de encuentros y conferencias entre los países del continente, entre ellas las vinculadas con la Cultura Física, la Educación Física, la salud y el mundo deportivo.
} 
educativas das repúblicas americanas, na coordenação das atividades deste ramo da educação integral dos povos (Revista Brasileira de Educação Física, 1944: 32).

La concreción del evento en Brasil -y la búsqueda de acuerdos y colaboraciones entre los gobiernos y las instituciones educativas americanas- fue el inicio de una serie de importantes congresos materializados durante varias décadas, impulsados por un conjunto de actores sociales vinculados con el amplio y heterogéneo campo de la Educación Física, los deportes y la medicina aplicada a dichas prácticas. Estos eventos se realizaron en diversas ciudades de América con el fin de delinear una política corporal panamericana que combinó la búsqueda de narrativas corporales regionales unificadas, con la coexistencia de discursos sobre la educación de los cuerpos con un tono nacional y soberano. En este contexto, con diversos intereses y finalidades, se realizó el Segundo Congreso Panamericano de Educación Física en México en octubre de 1946.

El siguiente trabajo explora y analiza, a partir de una historia social, política y cultural de la educación (Arata y Pineau, 2019), las problemáticas, los ejes semánticos y los saberes abordados, quiénes fueron los y las participantes, sus inserciones institucionales, sus trayectorias, las redes de intercambio fabricadas y los grupos ocupacionales presentes en dicho espacio. Pensamos al Segundo Congreso Panamericano de Educación Física como un lugar que permite identificar discursos en común, lógicas de sentido dominantes, discontinuidades temáticas y puntos de discordia sobre la educación del movimiento. Asimismo, exploramos el evento -el primero en su tipo y magnitud en México- como una caja de resonancia que visibiliza acuerdos, alianzas y conflictos entre personas, organizaciones y grupos de especialistas o expertos (Neiburg y Plotkin, 2004), los cuales pugnaron por imponer ciertos sentidos y significados en el campo específico. Nuestra hipótesis sugiere que el evento, con continuidades y rupturas de sentidos en los discursos, saberes y prácticas de la educación física, se convirtió en un terreno no sólo de legitimación -y auto celebración- de la especialidad en términos trans-nacionales, sino también de jerarquización y de mayor visibilización de ciertos países, expertos e instituciones por encima de otras.

\section{La Educación Física: su emergencia histórica}

El Segundo Congreso Panamericano de Educación Física se realizó en un contexto en el que tanto la disciplina educativa como la formación del profesor de educación física estaba en plena expansión y crecimiento en la mayoría de los países americanos. De hecho, la constitución de la educación física como disciplina escolar ya tenía más de un siglo y medio de existencia en algunos países europeos. Esto se debió a que su institucionalización estuvo 
vinculada estrechamente con la invención de los sistemas educativos modernos en occidente (Vigarello, 2005; Kirk, 2010; Ljunggren, 2011).

En Europa su origen se ubica a finales del siglo XVIII y principios del XIX. En especial, en las primeras décadas del siglo XIX, junto con una nueva 'visión' sobre los cuerpos y su funcionamiento, se produjo un novedoso tratamiento físico sobre los mismos. En algunos gimnasios inaugurados en Londres, París, Berlín o Berna, los cuerpos fueron objeto de un tratamiento particular, cuyo objetivo central fue la medición, el cálculo, la precisión, la eficiencia y la cuantificación de las posiciones, de los movimientos y de los desplazamientos corporales. Poco a poco se fueron constituyendo los diferentes sistemas, escuelas o métodos gimnásticos, entre los que se destacaron el francés, el sueco y el alemán. Todos ellos construidos y nutridos a partir de los principios de importantes representantes del discurso pedagógico moderno, tales como Johann Heinrich Pestalozzi, Johann Bernhard Basedow, Jean-Jacques Rousseau o Christian Salzmann. El combate por definir e imponer sobre los cuerpos, sentidos y significados morales y políticos más que físicos y somáticos, quedó abierto (Vigarello y Holt, 2005; Scharagrodsky, 2011).

Algunos referentes ilustrados como Francisco Amoros, Phokio Clias, Pehr Henrik Ling, Guths Muths, Friedrich-Ludwing Jhan, Adolph Spiess y, posteriormente, Etienne-Jules Marey, Georges Demeny, Fernand Lagrange, Philippe Tissie, Napoleón Laisné o Angelo Mosso se ubicaron, en el largo siglo XIX, entre los 'primeros' promotores de un tipo particular de educación física y corporal. Más allá de diferencias conceptuales, metodológicas y/o personales -en algunos casos muy pronunciadas- sus propuestas sobre la educación, la regulación y el control de los cuerpos encontraron su justificación en una serie de cambios políticos, sociales, económicos, militares y demográficos ocurridos en ese siglo. En nombre de la expansión de la vida en las ciudades europeas; de la imposición paulatina de nuevos códigos de moralidad y civilidad modernas; de los incipientes cambios en los procesos de industrialización; de los 'excesos' y los 'peligros' de la creciente vida urbana; de la emergencia de los ejércitos modernos, de los estados nacionales y de ciertos nacionalismos; del surgimiento del estado educador; del temor ante la ambigüedad de ciertos comportamientos corporales masculinos y femeninos; de la necesidad de regenerar cuerpos y poblaciones; de un interés por el cuidado y el mejoramiento de la 'raza'; de la persecución afanosa de un equilibrio entre lo intelectual, lo moral y lo físico; de la búsqueda de un tipo particular de endurecimiento físico -y espiritual- de los futuros defensores de la nación; de un resurgimiento del interés por el regreso a la 'naturaleza'; de la lucha contra ciertas enfermedades asociada a la promoción de un determinado estilo de vida higiénico; se instaló y legitimó la gimnasia, la educación física escolar y las demás propuestas de educación corporal ligadas a ella (deportes, juegos, campamentismos, excursionismos, paseos, bailes, danzas, etc.) (Scharagrodsky, 2011). 
Este heterogéneo conjunto de preocupaciones decimonónicas, en principio acotadas a un universo pequeño y urbano, penetraron muy lentamente en la vida cotidiana y en un conjunto de instituciones, entre las que se destacaron, las fuerzas armadas, los colegios y las escuelas. Si a inicios del siglo XIX la sistematización y especialización de ciertos discursos y prácticas sobre la educación de los cuerpos fue un asunto menor y relativamente insignificante; a finales del siglo XIX el panorama cambió drásticamente. A ello se le sumaron los deportes inventados y difundidos de manera cuasi-imperial por Inglaterra y EEUU a partir de mediados del siglo XIX (Mangan, 1998). Ningún actor social vinculado con el discurso médico o pedagógico dominante osó rechazar la necesidad, en algún punto compulsiva, del ejercicio físico -y los deportes- en niños, niñas, jóvenes, adultos y ancianos. Estas ideas europeas -y en menor medida de EEUU- llegaron a Latinoamérica y se resignificaron. Los contextos locales establecieron nuevos sentidos a la educación de los cuerpos destacándose figuras latinoamericanas como Enrique Romero Brest, Manuel Velázquez Andrade, Jorge Bejarano, Alejandro Lamas, Joaquín Cabezas o Fernando de Azevedo. Estos referentes disciplinares, mantuvieron a las escuelas, a los colegios, y en menor medida, a los gimnasios, a los parques y a las plazas, como alguno de los lugares escogidos para educar los cuerpos en movimiento a partir de ciertos discursos bio-médicos e higiénicos, pero resignificándolos a partir de las peculiaridades, las tensiones y las necesidades locales de la mayoría de los países americanos (Soares, 2001; Herrera Beltrán, 2008; Moctezuma, 2011; Scharagrodsky, 2015; Góis, 2015; Dogliotti, 2016; Reggiani, 2019).

En este contexto, México a mediados de los años cuarenta también tenía un largo recorrido de propuestas vinculadas con la educación física, la gimnasia y los deportes dentro y fuera de las instituciones educativas. Según Moctezuma la educación física en México inició un largo proceso de institucionalización a partir de 1874 cuando se señaló la necesidad de "impartir una clase de gimnasia en las escuelas primarias mexicanas de ambos sexos las cuales dependían directamente del Ministerio de Instrucción Pública". Este primer momento se caracterizó, como en la mayoría de los países americanos, por una fuerte influencia europea (gimnasias suecas, francesas, alemanas, etc.) y "los primeros esfuerzos por establecer la gimnasia y los ejercicios militares en México" (Moctezuma, 2011: 302).

Un segundo momento de la disciplina educativa estuvo vinculada con la influencia de los congresos pedagógicos en la formación del currículo escolar a partir de 1889 y 1890, en los cuales se potenciaron los juegos gimnásticos, los movimientos libres, las marchas y los ejercicios militares. En este segundo momento, que se prolongó hasta 1921,

se inauguraron la Academia Gratuita de Gimnástica Sueca (1904); Ia Asociación Gimnástica Racional y Juegos al Aire Libre (1905); la primera Escuela Magistral de Esgrima y Gimnasia (1907) que ofrecía por primera vez una formación específica para profe- 
sores con una orientación de corte militar y la Asociación Mexicana de Educación Física (1908), para la formación del maestro de gimnasia que atendía a las escuelas normales o primarias. En este momento la formación se debatía entre dos sistemas: la gimnasia alemana o con aparatos (buscaba la formación atlética y militar) y la sueca (se priorizaba la salud sobre el vigor) (Moctezuma, 2011: 308-309).

En este período se fueron delineando, como en muchos otros países americanos, ciertos guiones generalizados sexualizados los cuales subalternizaron a las niñas a la hora de acceder y practicar algunas gimnasias, juegos o ciertos deportes (Chávez González, 2006).

El tercer momento se produjo entre 1921-1940 de la mano del nuevo proyecto posrevolucionario con el fin de "regenerar biológica y estéticamente a la raza mexicana y civilizar las costumbres a través de la higiene corporal (...)" (Chávez González y Guzmán, 2018: 150). En 1921, se creó la Secretaría de Educación Pública (SEP) con lo cual se planteó un nuevo proyecto de educación. José Vasconcelos, Secretario de Educación, planteó de manera central "estimular al niño a través del ejercicio, la salud física y la espiritual, que eran los componentes principales de este proyecto". Para esto se creó, en 1923, la Dirección General de Educación Física. "En esta propuesta se rescataron también las danzas y el folklore, entendidas como bienes culturales que preservaban el sentido de lo mexicano. También se incorporó la enseñanza de los deportes de origen anglosajón como el atletismo, el básquetbol, el voleibol, el fútbol y la natación". Asimismo, se inauguró la Escuela Universitaria de Educación Física (1927) con un enfoque higiénico-deportivo que promovía el cuidado de la salud. En los años treinta se delineó desde la SEP una visión comunitaria y socializadora que caracterizó el período del presidente Lázaro Cárdenas.

\begin{abstract}
A nivel nacional se creó el Departamento Autónomo de Educación Física y para formar a los profesores de la educación primaria se fundó en 1936 la Escuela Normal de Educación Física, que funcionó hasta 1943, con una formación nacionalista y patriótica. Los egresados promovieron las tablas gimnásticas y los ejercicios de orden y control, de influencia militar, tales como las tácticas y estrategias aplicadas a la enseñanza del deporte. Fue el período en el que llegan a México, una serie de deportes como el béisbol, el básquetbol y el fútbol siendo el modelo norteamericano de desarrollo físico un ejemplo a seguir, destacándose el papel de las misiones culturales en el México rural (Moctezuma, 2016: 305)3.
\end{abstract}

Entre 1943 y 1949, la Escuela Normal y Premilitar de Educación Física se organizó bajo un enfoque que ponía énfasis nuevamente en la concepción militar de la actividad física, acorde con las condiciones que caracterizaban la época de finales de la Segunda Guerra

\footnotetext{
${ }^{3}$ Ciertamente fue durante el cardenismo que se difundieron determinadas prácticas deportivas (béisbol, fútbol, básquetbol, etc.) a través de las misiones culturales y las escuelas.
} 
Mundial y los inicios de la postguerra (Moctezuma, 2011: 312-315). En este contexto se celebró, en la capital mexica, el evento panamericano.

\section{El congreso: su estructura, sus tópicos y sus discursos}

El Segundo Congreso Panamericano de Educación Física fue organizado por la Dirección Nacional de Educación Física y Enseñanza Premilitar, bajo regulación de la Secretaría de la Defensa Nacional de México. El evento fue presidido por una de las máximas autoridades militares: el General Antonio Gómez Velasco y se convirtió en un éxito transnacional ya que contó con la participación de delegados y asistentes de diecinueve países de América: Argentina, Brasil, Chile, Costa Rica, Colombia, Cuba, Ecuador, El Salvador, Estados Unidos, Guatemala, Honduras, Nicaragua, Panamá, Paraguay, Perú, Puerto Rico, Uruguay, Venezuela y México (Memoria oficial del II Congreso Panamericano de Educación Física, 1946: 343).

La presencia del Estado mexicano se hizo notar antes y durante el congreso. Por un lado, la Secretaría de Relaciones Exteriores se ocupó de divulgar el evento y envío las invitaciones formales a los diferentes países por los conductos diplomáticos. Por el otro, la organización estuvo a cargo de dos dependencias del gobierno federal, la Secretaría de la Defensa Nacional y la Secretaría de Educación Pública, las cuales apoyaron de manera política y económica el evento.

El tránsito por ciertos espacios convertidos en lugares (Malpas, 2015) con fuertes efectos performativos nos muestra la importancia que el estado mexicano le asignó al evento. En las dos semanas que duró el congreso se combinaron actividades y celebraciones en lugares emblemáticos de la capital mexicana. El acto inaugural -y de clausura- se realizó en la Sala de Espectáculos del Teatro de las Bellas Artes ante delegados y diplomáticos de los diferentes países, autoridades educativas nacionales, docentes y personas interesadas en el universo deportivo. Asimismo, se realizó un acto solemne en la guardia a los héroes en la Columna de la Independencia, se visitó la Tercera División de Infantería, el Estadio Nacional, el Campo deportivo 'plan sexenal', el Estadio Olímpico de la Ciudad de los Deportes (inauguración), el Estadio del Instituto Politécnico Nacional, la Escuela Normal de Educación Física, el campo de fútbol del parque 'Plutarco Elías Calles', entre otros espacios. Como era costumbre en muchos congresos, el evento visibilizó ante los delegados de los países participantes, la grandeza y la solidez de los nuevos espacios y de la arquitectura deportiva mexicana como símbolo de progreso sanitario, modernización y regeneración social y poder nacional. Se concretaron actos deportivos y gímnicos masivos y multitudinarios (formaciones gimnásticas multitudinarias, danzas y bailes regionales, demostración de algunos deportes en masa, etc.) realizados por escolares mexicanos en muchos de estos espacios. (Imagen I, Imagen II, Imagen III) 


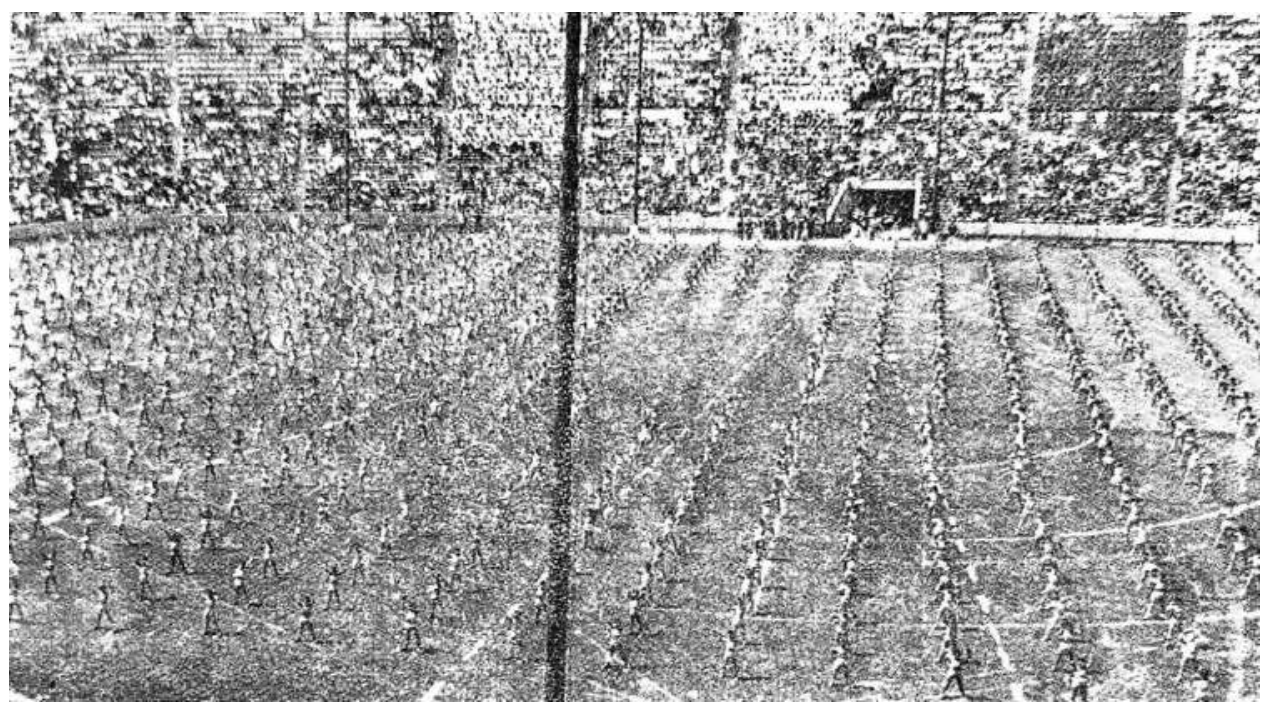

Imagen I. Exhibición gimnástica.

Fuente: Memoria oficial del II Congreso Panamericano de Educación Física, 1946: 349.

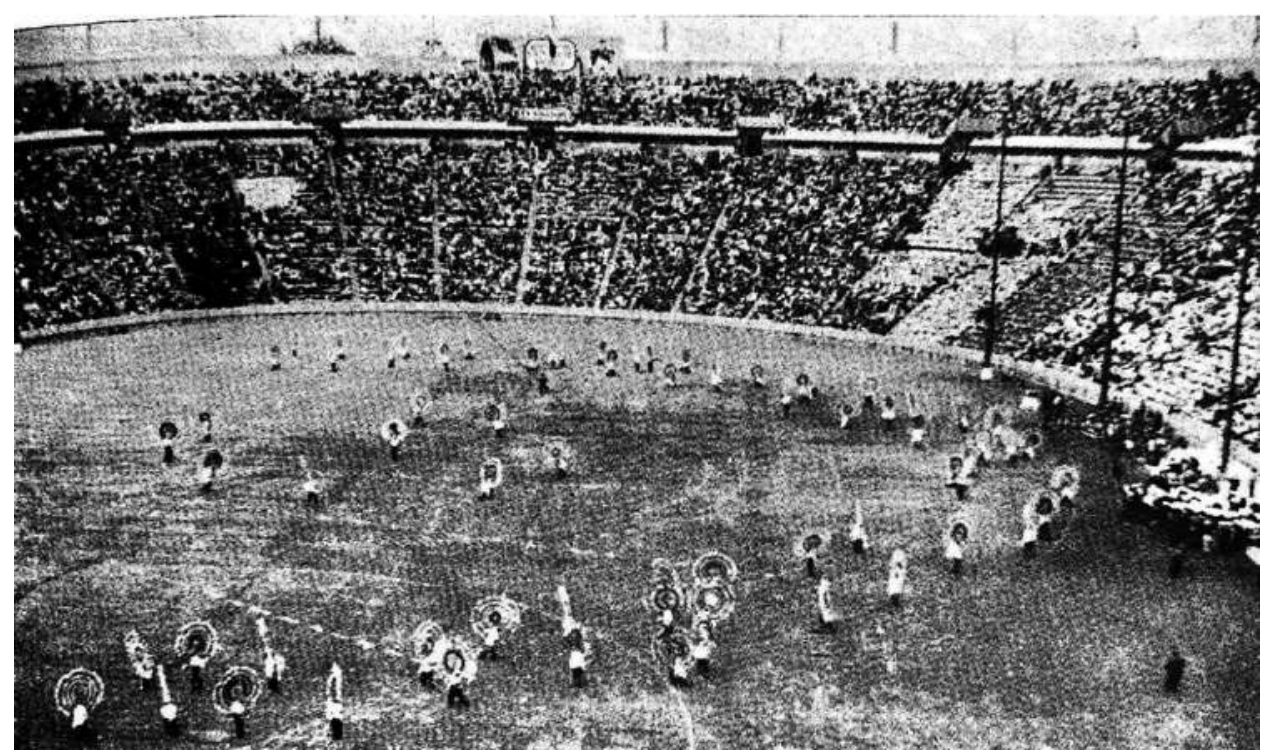

Imagen II. Exhibición gimnástica.

Fuente: Memoria oficial del II Congreso Panamericano de Educación Física, 1946: 340 


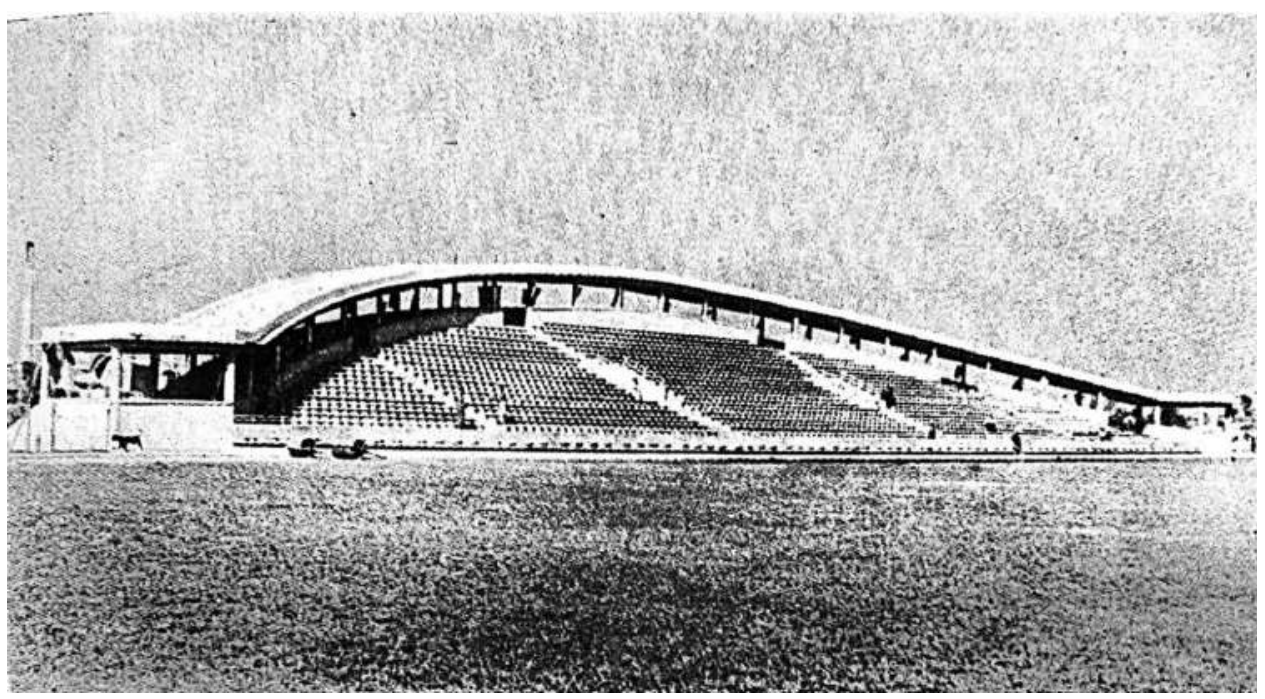

Imagen III. Una de las graderías del Campo de fútbol del Parque 'Plutarco Elías Calles' visitado por los señores congresistas.

Fuente: Memoria oficial del II Congreso Panamericano de Educación Física, 1946: 207.

En la inauguración del congreso estuvieron presentes importantes autoridades militares y educativas (General Francisco Urquiza, General Manuel Ávila Camacho, José Vasconcelos, etc.), diplomáticos y, muy especialmente, docentes de diversos niveles educativos y de la especialidad. Los distintos oradores combinaron la clásica retórica biopolítica asignada a la disciplina vinculada "al fortalecimiento del cuerpo y del individuo", "(...) a la salud de los pueblos" y de "su moral", a partir de lo "que la ciencia indica", junto con la exaltación de "(...) la grandeza interamericana", "la hermandad y fraternidad americana", "el progreso de los pueblos americanos" y "la cristalización de los postulados panamericanos" (Memoria oficial del II Congreso Panamericano de Educación Física, 1946: 109-113).

El tipo de organización programada durante el congreso nos brinda elementos sobre los tópicos planteados, los tipos de problematización realizados y los diferentes enfoques mencionados. Centralmente el evento estuvo organizado en seis grandes secciones: "Pedagogía y metodología de la Educación Física", "Biología, Medicina y ciencias aplicables a la Educación Física", "Organización de la Educación Física", "Política y sociología educacional", "Técnica deportiva y temas libres" y "Resoluciones" (Memoria oficial del II Congreso Panamericano de Educación Física, 1946: 24). 
Este tipo de organización dio cuenta de cierta selección temática, de determinadas perspectivas a la hora de abordar las mismas y de algunos procesos de exclusión -e inclusióndentro de la especialidad. Por un lado, se mantuvo la histórica presencia del discurso biomédico como el discurso científico, objetivo y probado a la hora de fundamentar, justificar y legitimar la intervención del docente de la especialidad. Entre los tópicos debatidos aparecieron con cierta recurrencia la cuestión sobre los estudios antropométricos en los escolares, el valor terapéutico de la gimnasia, la importancia de los ejercicios respiratorios, las competencias del médico especializado en Educación Física, los grados de eficiencia del aparato circulatorio, los fundamentos biológicos de la educación física femenina, el examen médico integral para escuelas, las pruebas de medición en Educación Física, la nutrición y la Educación Física, los criterios para la determinación del valor individual, el análisis de la mecánica del movimiento; así como otros temas que excedieron el campo específicamente educativo: las consideraciones del esfuerzo físico en la altura, el régimen de alimentación de los deportistas y atletas, la kinesiterapia en traumatología, la alimentación y el entrenamiento, los estudios funcionales y clínicos de deportistas en laboratorios, el ritmo de la glicemia durante el trabajo muscular, los síndromes de esfuerzo y pruebas de la aptitud funcional del corazón o el análisis de la tiamina en la orina (Memoria oficial del II Congreso Panamericano de Educación Física, 1946: 132-135, 156, 158, 162-163, 176, 235-239).

Para un amplio conjunto de temas tratados, la mirada bio-médica fue la que aportó el lugar de 'verdad' y de legitimación de la disciplina con efectos concretos en sus prácticas. Por ejemplo, en la sección denominada "Biología, Medicina y ciencias aplicables a la Educación Física" se discutió y aprobó que para todo agrupamiento homogéneo en una clase de Educación Física, se debía realizar "el examen médico integral, el biométrico y caracterológico y las pruebas de eficiencia física", descartando el índice Pignet y adoptando "el índice de Equilibrio Morfológico"4. Asimismo, se acordó la adopción de una ficha médica y la necesidad de determinar el tipo medio normal de los pueblos americanos y de cada país. También hubo recomendaciones sobre la alimentación y la nutrición infantil y de los jóvenes a partir de una dieta específica y detallada (vitamina B, valencias alcalinas, creatina, etc.) y la impugnación de la educación respiratoria en la escuela. La problemática de la mujer y el ejercicio físico fue una de las obsesiones que atravesó varias secciones del congreso debido a la importancia que desde finales del siglo XIX tenía el cuerpo femenino para la reproducción y la grandeza nacional (calidad y cantidad de la población) (Scharagrodsky, 2008). En particular se objetó aquellos que "privaban a la mujer de la oportunidad de realizar ejercicios físicos durante el catamenio (...)" aunque se recomendó "no realizar ejercicios físicos los días de la menarca",

${ }^{4}$ El Instituto Nacional de Pedagogía mexicano sugirió "la utilización del INDICE DE EQUILIBRIO MORFOLOCICO, LA TIPOLOGIA DEL DESARROLLO FISICO Y LA MEDIDA DE LA CAPACIDAD VITAL, como recursos útiles para el diagnóstico del 'valor individual' y como complemento del examen médico general de los alumnos de las escuelas primarias" (Memoria oficial del II Congreso Panamericano de Educación Física, 1946: 405). 
pero si "durante la menopausia" o "(...) durante el período de gestación y en el puerperio (...)" (Memoria oficial del II Congreso Panamericano de Educación Física, 1946: 271-279). Aunque los congresistas -mayoría varones- se pronunciaron a favor de ampliar el acceso a las niñas a una importante cantidad de prácticas físicas, al mismo tiempo, a partir de "fundamentos biológicos de la educación física femenina" se naturalizaron y estereotiparon posibilidades kinéticas vinculadas a la "implantación de la gimnasia rítmica y la danza como base de la enseñanza de la educación de la mujer" y a "programas diferenciales de educación física para cada sexo" (Memoria oficial del II Congreso Panamericano de Educación Física, 1946: 162163, 206, 376-378, 414-417).

Al mismo tiempo, en los márgenes del discurso bio-médico (anatómico, fisiológico, ginecológico, antropométrico, biotipológico, endocrinológico, etc.), en las diferentes secciones se debatieron aspectos pedagógico-didácticos vinculados, por ejemplo, con el carácter educativo del deporte en la escuela, la difusión de nuevos juegos y deportes, la defensa de la educación física como parte de la instrucción escolarizada, la formación del Profesorado de Educación Física y su función social, la educación física y la recreación en la zona rural, la recreación como medio de educación popular, la importancia de los parques infantiles y campamentos permanentes, la organización de competencias deportivas, el juego infantil organizado, las medidas para abolir el 'campeonismo's, el lugar de la Educación Física en los planes y en el horario escolar, las cuestiones sobre la progresión gimnástica, la valorización del placer, el gusto y el agrado por la práctica física, entre otros tópicos (Memoria oficial del II Congreso Panamericano de Educación Física, 1946: 146-147, 155-156,183, 187-188, 204205, 210, 215, 218, 230, 363).

De igual manera, en algunas secciones, con matices y porosidades, se destacó la prioridad pedagógico-didáctica a la hora de fundamentar las intervenciones desde la Educación Física. Por ejemplo, entre las conclusiones que se recomendaron en la sección "Pedagogía y metodología de la Educación Física" se resaltó el carácter educativo de la disciplina y se definió "como parte" y como "base de toda educación" con "un carácter bio-psico-socio-filosófico" (Memoria oficial del II Congreso Panamericano de Educación Física, 1946: 265-268). Esta definición fue una de las banderas del evento.

Asimismo, las secciones vinculadas con la "Técnica deportiva y temas libres" y las "Resoluciones" debatieron y acordaron una serie de cuestiones relacionadas al "carácter educativo, recreativo, higiénico y social que debía tener el deporte en la escuela", "la eliminación de la participación de grupos minoritarios con tendencia al 'campeonismo'”, la reivindicación del juego infantil, la difusión de "los juegos autóctonos", el estímulo de ciertos

\footnotetext{
5 El "campeonismo" fue una forma de entender la práctica deportiva a partir de la hiper valoración del éxito deportivo como la única meta educativa; así como la exaltación del rendimiento físico, la obsesión por la técnica deportiva y el lucimiento individual.
} 
deportes apropiados para la mujer, junto con el fomento "del boxeo en el último año de la escuela secundaria y en las escuelas profesionales (...)", las actividades recreativas y la necesidad de profundizar las disposiciones legales en la especialidad, entre otros temas (Memoria oficial del II Congreso Panamericano de Educación Física, 1946: 299-304).

Por otra parte, nuevos temas y destinatarios fueron abordados en el evento. Por ejemplo, citando el I Congreso Indigenista Panamericano realizado en México en 1940 (Memoria oficial del II Congreso Panamericano de Educación Física, 1946: 204), entre las recomendaciones de la sección "Política y sociología educacional" se instó a la realización de "programas de Educación Física para indígenas" divulgándose "los juegos y danzas autóctonas". No obstante, al mismo tiempo, se propuso estimular en los indígenas la realización de una "educación física recreativa" (Memoria oficial del II Congreso Panamericano de Educación Física, 1946: 293-296). Otros temas fueron abordados por algunas secciones construyendo nuevos destinatarios en el campo y legitimando la necesaria intervención del profesor en educación física. Entre ellos se discutieron trabajos sobre la importancia de la Educación Física para débiles mentales, sordos, imbéciles y ciegos (Memoria oficial del II Congreso Panamericano de Educación Física, 1946: 232-233).

Más allá de acuerdos y consensos entre los distintos congresistas, tanto a partir de los discursos bio-médicos como de los pedagógicos y didácticos, se discutieron varios temas que tuvieron que ser puestos a votación. Por ejemplo, entre las discusiones y conclusiones generadas en las distintas comisiones apareció la necesidad de "realizar ejercicios de corrección de actitudes viciosas" sólo a aquellos estudiantes "que necesiten corregir sus defectos de postura" y no a todos los alumnos (Memoria oficial del II Congreso Panamericano de Educación Física, 1946: 132). La cuestión femenina también fue objeto de discusión. Aunque algunas voces cuestionaron el atletismo para las mujeres, el tópico terminó siendo aprobado como una opción válida para el colectivo femenino (Memoria oficial del II Congreso Panamericano de Educación Física, 1946: 206).

Por otra parte, hubo tensiones expresadas en una reñida votación, sobre si considerar a la Educación Física como auxiliar importante de la enseñanza militar y premilitar debido a "diversas corrientes de opinión sobre pacifismo y militarismo". Algunos propusieron "impartir enseñanza premilitar bajo técnicos militares" mientras que otros congresistas manifestaron "que el presente congreso es de educadores (...) y que la preparación que muchos Ilaman premilitar debe estar en manos exclusivamente de educadores, es decir, de profesores de Educación Física (...)" (Memoria oficial del II Congreso Panamericano de Educación Física, 1946: 148, 151).

También hubo discusiones sobre el mejor tipo de prueba para juzgar la eficiencia del aparato circulatorio. Algunos estuvieron a favor de la prueba Schnaider y otros de la Martinet (Memoria oficial del II Congreso Panamericano de Educación Física, 1946: 158). En cuanto 
al uso de las mediciones en educación física, tópico central en el evento, el delegado de EEUU (Frank Sttaford) objeto muchas de las consideraciones aceptadas por el resto de los congresistas:

\begin{abstract}
...en el segundo congreso se han aprobado ponencias cuyos fundamentos son rebatibles. En mi país he participado activamente de investigaciones antropométricas y se ha llegado al resultado de que no siempre estas pruebas conducen a determinar con precisión la situación biológica del individuo. (...) por ejemplo, si tratamos de medir el cráneo de un individuo, las diferentes medidas de alto y ancho, serían exactas, pero no nos diría nada en cuanto a la inteligencia de la persona sometida a la prueba (Memoria oficial del II Congreso Panamericano de Educación Física, 1946: 179).
\end{abstract}

Algunas voces comenzaron a alejarse de las afirmaciones provenientes de la medicina constitucionalista -fuertemente instaladas en varios países de América (Dorotinsky, 2012)la cual contiene miradas lineales, esterotipantes y violentas sobre los rasgos del cuerpo como signos más profundos de verdades psíquicas, morales o emocionales. Asimismo, el Doctor Mc Cloy de EEUU señaló que "no comparto el entusiasmo de algunos oradores en cuanto a la tesis de Schanider. (...) su confiabilidad es baja (...) (Memoria oficial del II Congreso Panamericano de Educación Física, 1946: 182-183). También hubo tensiones a la hora de definir diferentes criterios para hablar de la progresión gimnástica. Algunos adoptaron la progresión Skastrom y otros el método Hebert (Memoria oficial del II Congreso Panamericano de Educación Física, 1946: 230).

En conclusión, los tipos de secciones dispuestas, los tópicos discutidos, los diversos registros epistémicos configurados, los nuevos temas y destinatarios condensaron gran parte de las preocupaciones instaladas por los delegados nacionales y demás participantes sobre el campo de la educación física manteniendo (el discurso bio-médico) y, al mismo tiempo, tramitando nuevos sentidos sobre la especialidad (el discurso pedagógico y didáctico), sus finalidades y sus competencias.

\title{
3. El evento: entre finalidades corporativas, nacionales y panamericanas
}

Pero el Segundo Congreso Panamericano de Educación Física no sólo se convirtió en un espacio en el que se jerarquizaron ciertos saberes y discursos por encima de otros: bio-médicos (sobre todo en relación a la medición física) y pedagógico-didácticos (especialmente la visibilización del carácter educativo) o se consolidaron nuevos tópicos, ciertos tonos y determinados destinatarios (enseñanza de ciertos deportes, introducción de juegos autóctonos, crítica al 'campeonismo' escolar, reconocimiento del placer en la práctica física, incor- 
poración/asimilación de los indígenas a las políticas corporales modernas, etc.). Como cualquier evento internacional fue un lugar donde se instalaron demandas -muchas de ellas, con el tiempo, materializadas- y reclamos corporativos a ciertos actores sociales, con el fin de consolidar la función bio-médica y educativa de este grupo ocupacional moderno. De esta manera, por ejemplo, la sección relacionada con la "Organización de la Educación Física" resolvió recomendar y reclamar la indelegable "responsabilidad del Estado a la hora de organizar y planificar" dicha especialidad en términos de direcciones, capacitaciones o creación de infraestructura deportiva y recreativa (Memoria oficial del II Congreso Panamericano de Educación Física, 1946: 283-289).

La apelación al Estado y su indelegable rol biopolítico a partir de la cultura física, la educación física y los deportes fue una constante del congreso y atravesó casi todas las secciones y discusiones en un contexto nacional e internacional en el que las políticas corporales de entre guerra adquirieron múltiples e importantes funciones políticas, educativas, económicas, militares, diplomáticas e imperiales (Dyreson, 2011). Se insistió en la necesidad de aprobar leyes nacionales de Educación Física y organismos que la orienten, fiscalicen y fomenten, así como la disposición de fondos para su difusión y enseñanza (Memoria oficial del II Congreso Panamericano de Educación Física, 1946: 192).

De igual manera, se propusieron leyes y decretos gubernamentales que "marquen al Estado la obligación de instalar, constituir y conservar centros de Educación Física y Recreación (...), así como destinar parte de la recaudación fiscal para apoyo de actividades físicodeportivas" (Memoria oficial del II Congreso Panamericano de Educación Física, 1946: 409). Muchas de estas iniciativas ya estaban presentes en varios países como lo atestiguaron los testimonios y balances de los delegados oficiales de los países participantes, las cuales, con el paso de las décadas, se ampliaron y potenciaron.

El evento difundió el espíritu claramente corporativo de la especialidad, delimitó sus funciones, sus competencias y potenció su necesaria intervención en ciertos espacios (escuelas, colegios, clubes, plazas de juego, direcciones estatales, etc.) y lo posicionó frente a sus potenciales competidores: "(...) el deporte debe ser vigilado y conducido preferentemente por un profesor de educación física, (...)". También, se aprobó que "si el profesor de Educación Física no es a la vez kinesiólogo, el kinesiólogo no es profesor de educación física y no puede invadir el campo de éste" (Memoria oficial del II Congreso Panamericano de Educación Física, 1946: 146, 158).

Pero fue el discurso panamericano el que le ofreció múltiples posibilidades de acción a este particular grupo ocupacional. En el congreso se crearon algunas organizaciones que, con el tiempo, se convirtieron en espacios transnacionales muy importantes a la hora de conseguir recursos materiales -y simbólicos- de parte del Estado y de organizaciones deportivas de la sociedad civil. Fue en México donde se fundó la Confederación Panamericana de Asociaciones 
de Educación Física con el fin de "estrechar lazos continentales" y defender "los intereses fundamentales de los profesores de Educación Física" (Memoria oficial del II Congreso Panamericano de Educación Física, 1946: 243).

La retórica panamericanista en el campo de la educación corporal y deportiva combinó, en un difícil y ambiguo equilibro, "ficciones somáticas" (Nouzeilles, 2000) panamericanas con cuestiones supuestamente nacionales: "a pesar de las características especiales de cada nación, se buscan fijar normas generales comunes" (Memoria oficial del II Congreso Panamericano de Educación Física, 1946: 265). En la sección "Pedagogía y metodología de la Educación Física" se instó a formular un plan panamericano de Educación Física que atienda las "necesidades particulares de cada nación" (Memoria oficial del II Congreso Panamericano de Educación Física, 1946: 265-268). Respetando las particularidades nacionales, entre los universos 'comunes' reivindicados en el congreso, se mencionó insistentemente el acervo cultural 'propiamente' americano, el cual funcionó como sinónimo de distinción geopolítica positiva frente a la mirada -y a las intervenciones corporales y deportivas- de otras regiones del mundo moderno: "(...) el juego, las rondas, las danzas y los cantos utilizados en el juego infantil de los pueblos de América, (son) medios de conocimiento internacional" (Memoria oficial del II Congreso Panamericano de Educación Física, 1946: 299, 204). (Imagen IV)

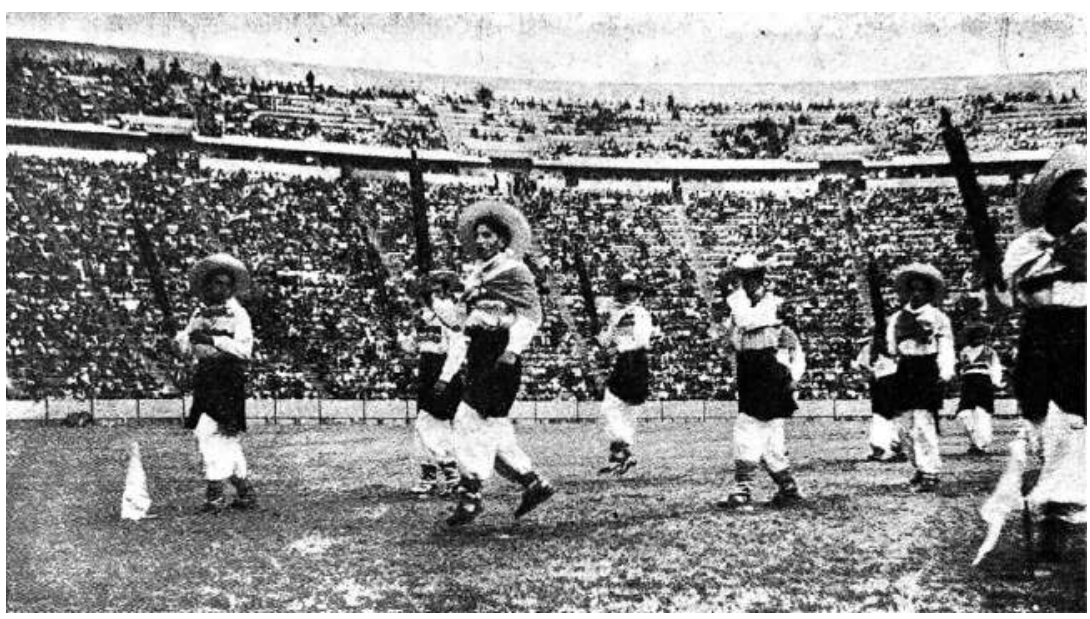

Imagen IV. Baile típico.

Fuente: Memoria oficial del II Congreso Panamericano de Educación Física, 1946: 353. 
La lógica panamericana se consolidó en México con actos concretos como la exposición Panamericana de Educación Física (Memoria oficial del II Congreso Panamericano de Educación Física, 1946: 240), la cual no sólo alimentó una cierta tradición corporal 'inventada' sino que, al mismo tiempo, generó una jerarquización y competencia de posiciones entre los diferentes países que mostraron a partir de fotografías, cuadros, organigramas, prácticas locales y objetos sus logros y progresos deportivos, estéticos, corporales, arquitectónicos y educativos, enlazando y asociando metonímicamente la grandeza del cuerpo individual con el cuerpo social y nacional. (Imagen V)

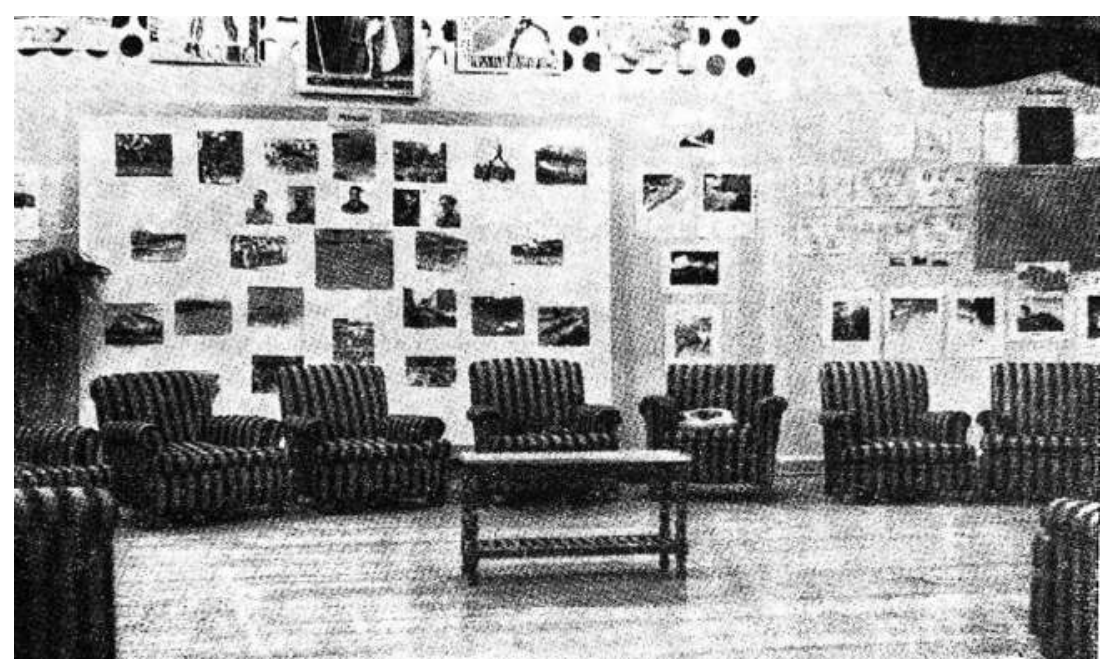

Imagen V. Exposición Panamericana de Educación Física.

Fuente: Memoria oficial del II Congreso Panamericano de Educación Física, 1946: 240.

También, el congreso consolidó ciertos rituales corporales y algunas exhibiciones con tonos nacionales, altamente generalizados, que ya se venían realizando en diversos países, incluido el México posrevolucionario (Chávez González, 2009). Las exhibiciones corporales que se organizaron potenciaron un campo corporal de lo visible y lo invisible (Sontag, 2006), de lo bello y de lo feo, de la sano e insano, de lo moral e inmoral, de lo femenino y lo no femenino, y de lo masculino y lo no masculino. (Imagen VI) La grandeza mexicana fue exaltada durante las manifestaciones corporales en estadios ante miles de espectadores $y$, en muchos casos, dicha grandeza se enlazó a todo el continente americano. José Vasconcelos, entre otros oradores, al inaugurar el congreso mencionó lo siguiente: 
País de charros, el nuestro, como casi todos los demás del Continente, no es raro que haya podido distinguirse en suertes tradicionales como las del lazo y el rodeo y los más modernos concursos hípicos de todo género. El hombre de a caballo ha sido el símbolo de América y hoy lo saludamos con melancolía (Memoria oficial del II Congreso Panamericano de Educación Física, 1946: 120).

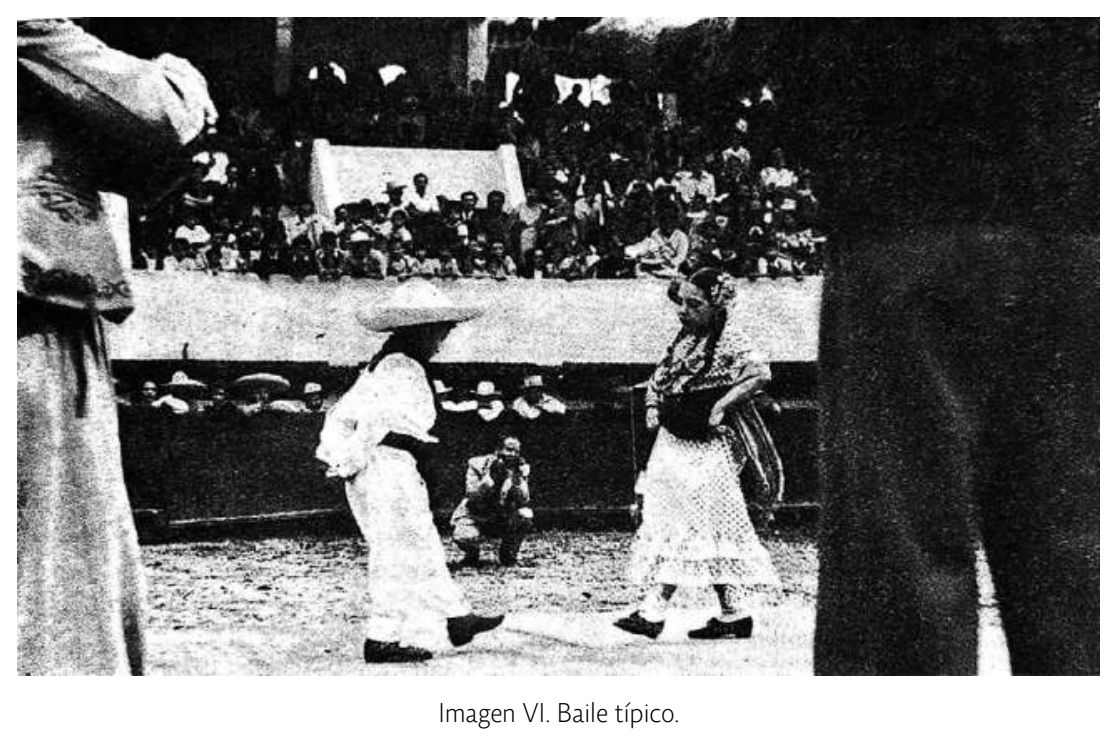

Fuente: Memoria oficial del II Congreso Panamericano de Educación Física, 1946: 307.

Aunque la retórica nacional propia de cada país estuvo presente en las discusiones y en los discursos del evento, la búsqueda de una proyección panamericana en el campo corporal, gímnico, lúdico y deportivo se materializó a partir de muchas acciones. Además de la creación de la Confederación Panamericana de Asociaciones de Profesores de Educación Física, se instituyó el Día Panamericano de Educación Física declarándose el 12 de octubre (Memoria oficial del II Congreso Panamericano de Educación Física, 1946: 190, 289). Ambas medidas, con los años, fueron muy efectivas en términos simbólicos y excedieron el campo de la disciplina educativa. Junto con estas medidas se buscó establecer una "Estadística de la Educación Física Panamericana" a partir de una "ficha individual panamericana" (Memoria oficial del II Congreso Panamericano de Educación Física, 1946: 124, 167) y definir "deportes y pruebas atléticas convenientes a la mujer americana" (Memoria oficial del II Congreso Panamericano de Educación Física, 1946: 206). Asimismo, se instó a lograr el "reconocimiento de los títulos (de los profesores) de los diferentes países" (Memoria oficial del II Congreso Panamericano de Educación Física, 1946: 286). 
En síntesis, el panamericanismo en este evento fue una retórica con tonos corporativos que incluyó y fusionó positivamente lo nacional y lo americano y, al mismo tiempo, se convirtió en una política con variados logros materiales la cual permitió consolidar y legitimar a la especialidad, justificar su lugar y potenciar a ciertos agentes, instituciones y redes transnacionales.

\section{Instituciones, personas, grupos ocupacionales y redes}

El congreso no sólo se convirtió en un espacio corporativo con finalidades nacionales y, sobre todo, transnacionales, sino que se configuró como un terreno en que se legitimaron ciertos agentes, grupos, países y redes por encima de otras.

Entre las distintas instituciones presentes en el evento, es posible mencionar para el caso mexicano a representantes de la Secretaría de la Defensa Nacional, la Secretaría de Educación Pública, la Dirección Nacional de Educación Física y Enseñanza Premilitar, la Escuela Normal de Educación Física, el Colegio Nacional de Profesores de Educación Física, la Confederación Americana de Magisterio, la Asociación Cristiana de Jóvenes, el Comité Olímpico Mexicano, el Instituto Nacional de Nutriología, la Delegación Sindical de Profesores de Educación Física, el Club de Golf 'Azteca', entre otras.

Para el caso panamericano hubo diversas instituciones que se hicieron presentes en el congreso. Su variedad condensó instituciones de diverso tipo: especialmente estatales vinculadas a la gestión de la cultura física, la higiene, la educación, clubes deportivos, asociaciones particulares e inclusive instituciones de formación terciaria y universitaria ${ }^{6}$.

Entre las figuras mexicanas presentes en el congreso se destacaron el Dr. Ernesto Pérez Fuentes, el Dr. Samuel Terrazas, el Dr. Francisco Contreras, el Dr. Salvador Ojeda, los profesores Antonio Stopier (Director de la Escuela Normal de Educación Física), Juan Snyder Lasseter (representante del Comité Olímpico Mexicano), Hugo del Pozo (Presidente del Colegio Nacional de Profesores de Educación Física), Rubén López Hinojosa (secretario del Congreso), Alfredo Palacios Almoniet, Salvador Calderón Álvarez, Salvador Lecona, Ignacio Rodríguez Vallarta, Horacio Samperio Ortiz, el General Gómez Velasco, el General Manuel Celis, el Coronel Carlos Altamira, el Teniente Coronel Lamberto Álvarez Gayou y un grupo de

\footnotetext{
${ }^{6}$ Entre ellas, se destacaron las Direcciones de Higiene, Educación o Educación Física (Comisión Nacional de Educación Física de Uruguay, Conservatorio Nacional de Educación Física de Perú, División de Educación Física del Ministerio de Educación y Salud de Brasil, Oficina de Educación Física de Venezuela, Servicio Médico de la Asociación Cristiana de Jóvenes, Servicio de Educación Física de Pensilvania, etc.) representadas por delegados oficiales nombrados por los gobiernos de las naciones americanas participantes, agrupaciones y asociaciones de maestros de la especialidad de los diferentes países (Asociaciones de Profesores de Educación Física de Chile, Colombia, Argentina, Brasil, etc.), instituciones de formación superior (Universidad de Lima, Universidad Interamericana de Panamá, Academia Americana de Educación Física, etc.), entre otras.
} 
profesoras entre las que sobresalieron Alura Flores Barnes, Luz Merino Araus, Consuelo Chávez, Bertha Gutiérrez Sánchez, entre otras.?

El congreso aglutinó a una diversidad de personas, especialistas y nacionalidades ${ }^{8}$, con diferentes trayectorias formativas e institucionales. La mayoría de los expositores estuvieron relacionados con el universo de la educación formal. Casi totalidad fueron docentes de la especialidad, en general egresados de escuelas o institutos de formación del área y, en algunos casos, con otras titulaciones, vinculadas con el magisterio en general. También se destacaron expositores con formación bio-médica, la mayoría de ellos egresados, a diferencia de los especialistas en educación física o en educación, de instituciones universitarias: Facultades de Medicina de los diferentes países participantes. De este campo sobresalieron los médicos deportólogos o médicos interesados en un tema vinculado directa o indirectamente con la cultura física y deportiva, como los galenos nutricionistas. También hubo una importante cantidad de expositores relacionados con el campo militar, producto del contexto político vinculado con la segunda guerra mundial.

Entre las personas mencionadas anteriormente vinculadas a la enseñanza de la educación física, se destacaron algunos profesores que no solo ejercieron la docencia en instituciones educativas, en espacios recreativos (públicos o privados) o trabajaron en instituciones deportivas particulares, sino que produjeron discursos 'verdaderos' y modos de intervención adecuados sobre la especialidad. Muchos de ellos escribieron manuales o textos los cuales circularon dentro y fuera del campo pedagógico, en revistas especializadas de educación o de divulgación (periódicos de tirada nacional) sobre temáticas referidas a la cultura física. Algunos trabajaron en las instituciones de formación, siendo responsables de la educación de los futuros profesores de educación física y/o aportando material específico para la formación del magisterio en la mayoría de los países participantes. Un importante número de expositores ejercieron cargos - de segunda o tercera línea- en la función pública y, en muchos casos, se vincularon con la burocracia estatal educativa. Otros formaron parte en la

7 Entre los casi 50 delegados nacionales mexicanos hubo congresistas provenientes de diversas regiones: Aguascalientes, Baja California, Campeche, Colima, Chihuahua, Distrito federal, Durango, Guerrero, Jalisco, Michoacán, Morelos, Oaxaca, Puebla, San Luís Potosí, Sinaloa, Sonora, Tabasco, Tamaulipas, Tlaxcala, Veracruz, Yucatán, etc.

8 Entre las ponencias y participaciones de 'referentes' extranjeros los hubo de Brasil (Mayor Juan Barbosa Leite, Dr. Waldemar Areno, Dr. Inezil Penna Marinho, Capitán Jacinto Francisco Targa, Dr. y Capitán Ruy Gaspar Martins, profesora Silvia Márquez, Celina Figueira Da Motta), Chile (profesor Víctor Seguel, Martha Briceño, Dr. Luis Bisquertt, Dr. Jorge Mardones, Dr. Héctor Croxatto), Costa Rica (Dr. Eugenio García Carrillo, profesor Alfredo Cruz), Colombia (profesor Alberto Gómez, Carmen Dueñas, Juan Pardo), Cuba (Dr. Rubén Barraza, Dr. Delio González, profesor Arturo Feffer), Ecuador (Ing. Luis Felipe Donoso), El Salvador (profesor Jesús Espinoza, Dr. Rubén Barraza), Estados Unidos (Frank S. Stafford, Dr. Ben W. Miller, Dr. C. H. McCloy, John L. Barringer, Wilbur De Turk, Frank Williams, Catehrina Wilkinson, Hiawatha Crosslin, Dorothy Needham, Norma Young), Guatemala (Jorge Alberto Micheo), Honduras (profesor Luis Beltrán Gómez), Nicaragua (José Castillo Valladares), Panamá (Carlos Pretelt, Jesús Ferrer Gamboa), Paraguay (Dr. César Adorno, Gral. Gilberto Andrada), Perú (Dr. César Beleván García, Dr. David Torres Calle, Dr. Evaristo Gómez Sánchez, Dr. Julio Pretto, Dr. Emilio Montoya Arce, Dr. Guillermo Saldívar, profesor Rubén García Cáceres, Coronel Leopoldo Jarrín), Puerto Rico (Julio Monagas), Uruguay (Julio Pereyra, Raúl Previtale, José Stern, Dr. José Faravelli Musante) y Venezuela (Coronel Juan Jones Parra, Dr. Ernesto Pérez Fuentes). El Dr. Inezil Penna Marinho ofició como representante de la Asociación de Profesores de Educación Física de la Argentina. 
orientación y el entrenamiento de la elite deportiva en cada uno de sus países, participando como responsables en torneos nacionales, americanos o europeos (Juegos deportivos centroamericanos, torneos deportivos sudamericanos, olimpiadas, etc.). Este selecto grupo difusor de sentidos sobre la cultura física y la educación física 'deseable ' correcta' y 'adecuada', participó en comisiones públicas debatiendo sobre políticas deportivas, educativas, recreativas y sanitarias nacionales, las cuales abundaron en la mayoría de los países americanos entre los años '20 y '30. Muchos de ellos, al ser considerados voces autorizadas en la especialidad, fueron invitados a congresos internacionales de educación, higiene, infancia, puericultura, eugenesia, etc.

Claramente el evento mostró y condensó centralmente a dos grupos de especialistas con cierta cohesión y jerarquía interna, interesados en administrar, gestionar y controlar las competencias, saberes e injerencias de la actividad gímnica, deportiva o recreativa y sus políticas: los profesores de educación física y los médicos deportólogos. Aunque en términos cuantitativos los médicos especializados en la Educación Física y deportiva fueron menos que los docentes en educación física, su prestigio, estatus, sus vinculaciones universitarias, su tipo de acreditación y su autoridad epistémica generaron mayor presencia e impacto a la hora de ejercer poder en el campo, especialmente con relación a la medición física y el certificado de salud, dos tópicos que venían obsesionando hacia décadas a dicha especialidad y a la educación en general.

Pero no todos los participantes en el evento -fuesen médicos, docentes o militarestuvieron la misma capacidad de generar influencia y autoridad. Hubo delegados de países que ejercieron mayores cuotas de poder, presencia y visibilidad. Entre los países con mayor injerencia en el evento es posible mencionar además de México -con su gran cantidad de participantes-, a Brasil que venía de organizar el primer congreso panamericano, a Chile con reconocidos e históricos referentes en la especialidad como el doctor Bisquertt o el profesor Víctor Seguel, que fue uno de los oradores principales en la inauguración del evento, a Perú que había sido nombrado en el primer congreso panamericano sede de la Secretaría General permanente del Congreso, y a Estados Unidos con su fuerte influencia en el universo deportivo sobre varios países americanos, así como por su participación durante el congreso (ofreció una de las 4 conferencias centrales) o su intervención en la sesión de clausura del evento junto con el embajador de Venezuela y el Secretario de Educación Pública, Jaime Torres Bodet. ${ }^{9}$

Las cuatro conferencias condensaron la centralidad de ciertos países sobre otros. Una conferencia estuvo a cargo del Dr. Luis Bisquertt (Director del Instituto de Educación Física

\footnotetext{
${ }^{9}$ La mayoría de los trabajos y ponencias que por asamblea se acordaron incluir en las voluminosas memorias fueron escritos por médicos y profesores mexicanos y brasileños (Memoria oficial del II Congreso Panamericano de Educación Física, 1946: 363-426).
} 
de Chile), otra fue ofrecida por el Dr. Inezil Penna Marinho (delegado de Brasil), otra presentada por el Dr. Mc Cloy (delegado de los Estados Unidos) y la última fue brindada por el profesor David Torres Calle (delegado de Perú). Los conferencistas fueron figuras determinantes de la educación física en sus respectivos países (Riobó y Villarroel, 2019; Oliveira, Schneider, dos Santos y Ferreira Neto, 2015; English, 1983).

Las delegaciones oficiales del país anfitrión y de los Estados Unidos fueron las más numerosas. Una de las claves para entender la capacidad de influencia de los diferentes países fueron las discusiones, las diferentes postulaciones y votaciones realizadas con el fin de dirigir el recién creado Instituto Panamericano de Educación Física. Para ejercer dicha institución hubo dos postulaciones: el profesor Raúl Blanco por Uruguay y el doctor Mc Cloy por los Estados Unidos, ganando la elección este último (Memoria oficial del II Congreso Panamericano de Educación Física, 1946: 254). Asimismo, se designaron 6 miembros para las "tres Américas" con varias postulaciones. Las mismas, luego de las votaciones, quedaron definidas de la siguiente manera: norte América: Profesor Rubén López Hinojosa (México) y el Dr. Frank Stafford (EEUU), centro América: Luis Beltrán Gómez (Honduras) y el Dr. Delio Conzález (Cuba) y sud América: el Dr. Luis Bisquertt (Chile) y el Mayor Juan Barbosa Leite (Brasil) (Memoria oficial del II Congreso Panamericano de Educación Física, 1946: 254-255). Entre los delegados de México, EEUU, Chile y Perú se fueron definiendo varias de las políticas y acciones de la especialidad.

Por último, de los más de 80 participantes (relatores) en el evento, hubo una amplia mayoría de varones. Fue en la sección médica, la de mayor legitimidad científica, donde más presencia masculina hubo: cerca del $90 \%$ de los participantes fueron médicos varones. No obstante, sí hubo doctoras en el congreso, algunas participaron y tuvieron una trayectoria muy destacada en la especialidad como, por ejemplo, la Dra. Mary Hiawatha Crosslin o la Dra. Norma Young, ambas norteamericanas. Sin embargo, a la hora de dirigir las instituciones su peso fue minúsculo. Por ejemplo, de los representantes de los dieciséis países firmantes del acta de fundación de la Confederación Panamericana de Asociaciones de Profesores de Educación Física sólo hubo una mujer, Martha Briseño, de Chile. A pesar de ello, como hemos señalado, la cuestión de la actividad física 'femenina' fue uno de los asuntos más tratados y debatidos en las diferentes secciones del evento, especialmente con relación al tipo de actividad física a realizar, la intensidad y gradación y los recaudos a tener en cuenta. La mayoría de las intervenciones sobre dicho asunto provinieron de parte de varones. Si bien los viejos conceptos bio-médicos sustentados en la teoría vitalista (Park, 2019) ya habían sido superados, en las intervenciones y recomendaciones se continuó naturalizando la división sexual de tareas y actividades (gimnasias, juegos y deportes para niñas), así como la esencialización de ciertas cualidades morales o físicas supuestamente femeniles durante el 
ejercicio o la práctica deportiva como la búsqueda de la gracia, la flexibilidad y la elegancia en los movimientos.

En síntesis, el evento condensó la centralidad de ciertas instituciones, algunos referentes (mayoría masculina), determinados grupos ocupacionales y ciertas redes transnacionales en las cuales algunos países sobresalieron por encima de otros.

\section{Conclusiones}

El Segundo Congreso Panamericano de Educación Física realizado en México en 1946 fue un espacio de discusión temática en donde los discursos bio-médicos y pedagógicos operaron consolidando a la Educación Física, sus competencias y sus intervenciones en tanto disciplina escolar y sanitaria. Hubo consensos y acuerdos temáticos vinculados con la necesidad de establecer estudios antropométricos en los escolares, afirmar el valor terapéutico de la gimnasia, destacar la importancia de los ejercicios respiratorios, las pruebas de medición y la alimentación, estimular el carácter educativo del deporte en la escuela, defender la educación física como parte de la instrucción escolarizada, difundir la recreación como medio de educación popular, abolir el 'campeonismo' y propagar la experiencia de los juegos autóctonos. Pero también discusiones y conflictos saldados a partir de reñidas votaciones: algunas voces cuestionaron el atletismo dirigido a las niñas y mujeres, objetaron la educación física como auxiliar importante de la enseñanza militar y premilitar, disintieron sobre el mejor tipo de prueba para juzgar la eficiencia del aparato circulatorio o discreparon sobre ciertos criterios utilizados en las mediciones físicas de los y las estudiantes.

En cualquier caso, este tipo de eventos reforzó no sólo la incorporación de la Educación Física en el dispositivo curricular de los diferentes niveles educativos (primario, secundario, terciario), sino también las múltiples posibilidades de intervención en otros espacios extraescolares a partir de la consolidación -simbólica, material y económica- de las direcciones de cultura física, deporte y educación física en los diferentes países.

El evento condensó finalidades corporativas, nacionales y panamericanas. Lo más novedoso fueron estás últimas las cuales incorporaron y, al mismo tiempo, fusionaron positivamente lo nacional y lo americano (reivindicaron los juegos y bailes autóctonos, el universo indigenista, etc.) produciendo y consolidando acciones propias de la especialidad (Confederación Panamericana de Asociaciones de Profesores de Educación Física, día Panamericano de la Educación Física, etc.). Lentamente, a partir de los años cuarenta se consolidaron lazos y redes transnacionales (Linhales, Rodrigues Puchta y Rosa, 2019).

Asimismo, el congreso potenció a ciertos agentes, instituciones, países y redes transnacionales. Entre las instituciones participantes se destacaron las públicas y estatales relacionadas a la gestión de la cultura física, la higiene, la formación y la educación. Muchos de los 
delegados -mayoría varones- de los países participantes fueron agentes estatales que se desempeñaron en direcciones educativas -nacionales o regionales- y las relativamente recientes direcciones de cultura física en la mayoría de los países americanos. Los grupos ocupacionales con mayor visibilidad en el evento fueron los profesores de educación física y los médicos interesados en el amplio campo de la cultura física. Si bien hubo docentes o médicos provenientes de las instituciones militares, la mayoría de los expositores estuvieron relacionados con el universo de la educación formal.

Por último, el evento puede ser leído como un terreno no sólo de acuerdos, sino también de disputas por erigir a ciertos países o determinados grupos en referentes del campo. Entre los delegados de países que ejercieron mayores cuotas de poder, presencia y visibilidad se destacaron los referentes de México, EEUU, Chile y Perú. En los futuros congresos panamericanos de Educación Física como el de Uruguay realizado en 1950, algunos países mantuvieron su autoridad en la especialidad, pero otros fueron desplazados. En cualquier caso, estos espacios con acuerdos y tensiones, visibilizaron, legitimaron y potenciaron a los profesores de Educación Física como agentes sanitarios, educativos y recreativos. En la segunda mitad del siglo XX, este grupo ocupacional 'menor' en el concierto de las profesiones modernas, sería un sigiloso y eficaz mediador de las políticas y programas de gobierno para la gestión de los cuerpos sanos y 'educados' en la mayoría de los países occidentales.

\section{Fuentes}

México (1946), Memoria oficial del I/ Congreso Panamericano de Educación Física, Editada por la Dirección Nacional de Educación Física y Enseñanza Premilitar.

Brasil (1944), "O QUE foi o I congresso panamericano de educação física", Revista Brasileira de Educação Física, Rio de Janeiro, ano I, núm. 1, jan., pp. 18-32.

\section{Referencias hemerográficas}

Chávez González, Mónica Lizbeth (2009), "Construcción de la nación y el género desde el cuerpo. La educación física en el México posrevolucionario", en Desacatos, CIESAS, núm. 30, mayo-agosto, México, pp. 43-58.

Chávez González, Mónica Lizbeth y Guzmán, Eugenia Macías (2018), "El patrimonio histórico educativo a través de las fotografías: la historia de la Educación Física en México" em Revista Iberoamericana do Patrimônio Histórico-Educativo, vol. 4, núm 1, jan-jun, Campinas, pp. 144-169

Dyreson, Mark (2011), "Imperial 'Deep Play': Reading Sport and Visions of the Five Empires of the 'New World', 1919-1941" in The International Journal of the History of Sport, vol. 28, núm. 17, pp. 2421-2447.

English, Eleanor B. (1983), "Charles H. McCloy. The Research Professor of Physical Education" in Journal of Physical Education, Recreation \& Dance, 54, 4, pp. 16-18.

Góis, Edivaldo (2015), "Georges Demeny y Fernando de Azevedo: una gimnasia científica y sin excesos (Brasil, Francia, 1900-1930)" em Revista Brasileira de Ciências do Esporte, vol. 37, abril-junio, Campinas, pp. 144-150. 
Malpas, Jeff (2015), "Pensar topográficamente: Lugar, espacio y geografía" en Documents d'Anàlisi Geogràfica, Universitat Autònoma de Barcelona, vol. 61, núm. 2, pp. 199-229.

Oliveira, Antonio Sergio Francisco; Schneider, Omar; Dos Santos, Wagner y Ferreira Neto, Amarílio (2015), "Inezil Penna Marinho: operaciones historiografía en educación física (1940-1958)" en Movimiento, vol. 21, núm. 2, abril / junio, Porto Alegre, pp. 291-302.

Riobó, Enrique y Villarroel, Francisco Javier (2019), "Belleza plástica, eugenesia y educación física en Chile: presentación de la fuente 'Aspectos de la educación física', de Luis Bisquertt (1930)" en História, Ciências, Saúde - Manguinhos, vol. 26, núm. 2, abr.-jun., Rio de Janeiro, pp. 673-693.

Scharagrodsky, Pablo (2015), "El Sistema Argentino de Educación Física. Entre el cientificismo, la higienización, el eclecticismo y la argentinidad" en Revista Brasileira de Ciências do Esporte, vol. 37, abril-junio, Campinas, pp. 158-164.

\section{Referencias bibliográficas}

Arata, Nicolás y Pablo Pineau (coords.) (2019), Latinoamérica: la educación y su historia. Nuevos enfoques para su debate y enseñanza, Editorial de la Facultad de Filosofía y Letras, Universidad de Buenos Aires, Buenos Aires.

Chávez González, Mónica Lizbeth (2006), "La introducción de la educación física en México: representaciones sobre el género y el cuerpo, 1882-1928", tesis de maestría en historia, El Colegio de San Luis, San Luis Potosí, México.

Dogliotti, Paola (2016), "Educación del cuerpo y discursividades en torno a la formación docente en la creación del Curso de Profesores de Educación Física en el Uruguay (1939-1948)" en Lucía Martínez Moctezuma (coord.), Formando el cuerpo del ciudadano. Aportes para una historia de la educación física en Latinoamérica, Editorial Universidad Autónoma del Estado de Morelos, México, pp. 49-83.

Dorotinsky, Deborah (2012), "Para medir el cuerpo de la nación: antropología física y visualidad racialista en el marco de la recepción de la biotipología en México" en Marisa Miranda y Gustavo Vallejo (dirs.), Una historia de la eugenesia. Argentina y las redes biotipológicas internacionales 1912-1945, Biblos, Buenos Aires, pp. 331-365.

Herrera Beltrán, Claudia Ximena (2008), "Prácticas corporales y subjetivación en el discurso pedagógico colombiano en la primera mitad del siglo XX" en Pablo Scharagrodsky (comp.), Gobernar es Ejercitar. Fragmentos para una historia de la Educación Física en Iberoamérica, Editorial Prometeo, Buenos Aires, pp. 49-64.

Kirk, David (2010), Physical Education Futures, Routledge, London.

Linhales, Meily, Rodrigues Puchta, Diogo y Rosa, María Cristina (org.) (2019), Diálogos Transnacionais na História da Educação Física, Fino Traço, Belo Horizonte.

Ljunggren, Jens (2011), "¿Por qué la gimnasia de Ling? El desarrollo de la gimnasia sueca durante el siglo XIX" en Pablo Scharagrodsky (comp.), La invención del 'homo gymnasticus'. Fragmentos históricos sobre la educación de los cuerpos en movimiento en Occidente, Editorial Prometeo, Buenos Aires, pp. 37-51.

Mangan, James Anthony (1998), The Games Ethic and Imperialism: Aspects of the Diffusion of an Ideal, Routledge, Londres y Nueva York.

Moctezuma, Lucía (2011), "Historia de la Educación Física en México" en Pablo Scharagrodsky (comp.), La invención del 'homo gymnasticus'. Fragmentos históricos sobre la educación de los cuerpos en movimiento en Occidente, Editorial Prometeo, Buenos Aires, pp. 299-320. 
(2016), "El cambio hacia un modelo norteamericano de educación física: las misiones culturales en el México rural, 1923-1940" en Lucía Martínez Moctezuma (coord.), Formando el cuerpo del ciudadano. Aportes para una historia de la educación física en Latinoamérica, Editorial Universidad Autónoma del Estado de Morelos, México, pp. 305-328.

Neiburg, Federico y Plotkin, Mariano (comps.) (2004), Intelectuales y expertos. La constitución del conocimiento social en la Argentina, Paidós, Buenos Aires.

Nouzeilles, Gabriela (2000), Ficciones somáticas. Naturalismo, nacionalismo y políticas médicas del cuerpo (Argentina 1880-1910), Beatriz Viterbo, Buenos Aires.

Park, Roberta (2019), "Fisiólogos, Médicos y Educadores Físicos. Biología y ejercicio higiénico y educativo en el siglo XIX" en César Torres y Pablo Scharagrodsky (edit.), El rostro cambiante del deporte. Perspectivas historiográficas angloparlantes (1970-2010), Editorial Prometeo, Buenos Aires, pp. 157-206. Reggiani, Andrés (2019), Historia mínima de la eugenesia en América Latina, El Colegio de México, México. Scharagrodsky, Pablo (2008), "Entre la histeria y la maternidad. Medicina, prácticas corporales y feminidad en el Buenos Aires del fin de siglo XIX" en Pablo Scharagrodsky (comp.), Gobernar es Ejercitar. Fragmentos para una historia de la Educación Física en Iberoamérica, Editorial Prometeo, Buenos Aires, pp. 105-135.

Soares, Carmen (2001), Educação física: raízes européias e Brasil, Editora Autores Associados, Campinas. (2da. Ed.).

Sontag, Susan (2006), Sobre la fotografía, Alfaguara, México.

Vigarello, Georges (2005), Corregir el cuerpo. Historia de un poder pedagógico, Nueva Visión, Buenos Aires.

Vigarello, Georges y Holt, Richard, (2005), "El cuerpo cultivado: gimnastas y deportistas en el siglo XIX" en Alain Corbin, Jean-Jacques Courtine y Georges Vigarello (dir.), Historia del cuerpo. De la Revolución francesa a la Gran guerra, Volumen II, Taurus, Madrid, pp. 295-354. 